\title{
IRBIT a master regulator of cell physiology
}

\begin{abstract}
Hormones and neurotransmitters regulate cell functions by binding to their receptors, which activate intracellular signaling and produce the physiological response. ${ }^{1}$ There are several intracellular pathways, including but not limited to, leading to the activation in protein kinases or phosphatases and increase of intracellular calcium $\left(\mathrm{Ca}^{2+}\right) .{ }^{1}$ Calcium signaling controls many cellular responses (e.g. exocytosiss, cell spreading, muscle contraction). Therefore it is important to understand the mechanisms regulating intracellular $\mathrm{Ca}^{2+}$. Two major sources exist to raise intracellular $\mathrm{ca}^{2+}$ : extracellular medium and internal stores (e.g., endoplasmic reticulum, mitochondria). While $\mathrm{Ca}^{2+}$ channels at the plasma membrane regulate $\mathrm{Ca}^{2+}$ entry in the cell, the inositol-1,4,5-trisphosphate receptor $\left(\mathrm{IP}_{3} \mathrm{R}\right)$ controls the release of $\mathrm{Ca}^{2+}$ from the endoplasmic reticulum. ${ }^{2,3}$ Many proteins are known to bind to the $\mathrm{IP}_{3} \mathrm{R}$ and regulate $\mathrm{Ca}^{2+}$ release. ${ }^{3,4}$ These include IRBIT (inositol-1,4,5-trisphosphate (IP ${ }_{3}$ ) receptors binding protein released with $\mathrm{IP}_{3}$ ), a protein discovered by Mikoshiba's group. ${ }^{4,5}$ Over the past decade IRBIT has emerged not only as an $\mathrm{IP}_{3} \mathrm{R}$ regulator but also as an important regulator of other cellular functions.
\end{abstract}

Volume 4 Issue I - 2017

\author{
Kelli Cook, Natasa Petreska, Patrice G \\ Bouyer \\ Department of Biology, Valparaiso University, USAs
}

Correspondence: Patrice G Bouyer, Department of Biology, Valparaiso University, USA Tel (219) 4645487, Fax (219) 4645489, Email patrice.bouyer@valpo.edu

Received: February 13, 2017 | Published: February 22, 2017

\section{IRBIT Regulates Intracellular $\mathrm{Ca}^{2+}$ Release from $I P_{3} R$}

The $I_{3} R$ interacts with specific proteins (e.g. Huntingtin, RACK1) and forms a macrocomplex that is believed to provide the diversity and specificity of the $\mathrm{Ca}^{2+}$ signaling. ${ }^{4}$ IRBIT was discovered while searching for novel binding partners of the IP ${ }_{3} R .^{5}$ IRBIT negatively regulates the $\mathrm{IP}_{3} \mathrm{R}$ by competing with $\mathrm{IP}_{3} .{ }^{6}$ IRBIT interaction with the $\mathrm{IP}_{3} \mathrm{R}$ (thus regulation of $\mathrm{IP}_{3}$ binding to its receptor) is decreased when IRBIT is phosphorylated as protein phosphatase (e.g. protein phosphatase 1) lowers IRBIT affinity to the $\mathrm{IP}_{3} \mathrm{R}$. Furthermore, phosphorylation of IRBIT's serine 68 plays a critical role in IRBIT inhibiting $\mathrm{IP}_{3}$ from binding to its receptor. ${ }^{6,7}$ In addition to the phosphorylation state of IRBIT, two motifs (PEST and PDZ) were identified by in-silico analysis. ${ }^{8}$ Pull-down assays with IRBIT missing the PEST or PDZ motif demonstrated that these two motifs are important for the binding of IRBIT to the $\mathrm{IP}_{3} \mathrm{R} .{ }^{8}$

\section{IRBIT a regulator of membrane transporter}

As pointed above, IRBIT is released from the $\mathrm{IP}_{3} \mathrm{R}$ after $\mathrm{IP}_{3}$ binds to its receptor. Thus Mikoshiba's group hypothesized that IRBIT could be a new signaling molecule that interacts with downstream targets. By screening proteins that can bind to IRBIT they found that IRBIT interacts with the electrogenic sodium bicarbonate, NBCe1-B variant (aka pancreatic isoform). Using a heterologous system to coexpress IRBIT and NBCe1-B, they showed by electrophysiological measurements that the transport activity of NBCe1-B is substantially increased in the presence of IRBIT. ${ }^{9}$ Another study demonstrated that IRBIT increases NBCe1-B activity by masking in part the auto inhibitory domain of NBCe1-B. ${ }^{10}$ These experiments suggest that IRBIT by increasing the activity of NBCe1-B, plays an important role in acid-base homeostasis.

The $\mathrm{Na} / \mathrm{H}$ exchanger 3 (NHE3) participates in sodium $\left(\mathrm{Na}^{+}\right)$ reabsorption in the kidney. Angiotensin II (a hormone elevating $\mathrm{Ca}^{2+}$ via $\mathrm{IP}_{3}$ ) increases $\mathrm{Na}^{+}$reabsorption by stimulating NHE3 in the kidney, ${ }^{11}$ but the mechanisms by which angiotensin II activates NHE3 are not clear. Using a yeast two-hybrid system He et al. found that IBIRT interacts with NHE3. ${ }^{12}$ In addition, knocking down
IRBIT abrogates the stimulatory effect of $\mathrm{Ca}^{2+}$ and angiotensin II on the activity of NHE3. ${ }^{12,13}$ These studies provide new ways of better understanding how angiotensin $\mathrm{II}$, via the $\mathrm{Ca}^{2+}$ signaling stimulates $\mathrm{Na}^{+}$reabsorption in the kidney.

In the pancreatic duct, fluid secretion is driven by an active transcellular secretion of bicarbonate $\left(\mathrm{HCO}_{3}^{-}\right)$. The basolateral NBCe1-B pumps $\mathrm{HCO}_{3}^{-}$inside the cell while the apical cystic fibrosis transmembrane regulator (CFTR) and $\mathrm{Cl} / \mathrm{HCO}_{3}$ exchanger SLC26a6 secrete $\mathrm{HCO}_{3}^{-}$in the pancreatic duct lumen. In addition to NBCe1-B, it was found that IRBIT binds to CFTR and SLC26a6 and increases transport activity of both transporters. The authors proposed that IRBIT coordinates the activity of basolateral and apical transporters involved in HCO-3-mediated fluid secretion. ${ }^{14,15}$ The results from these studies describe a new process allowing the crosstalk between the apical and basolateral membrane.

Finally, IRBIT has also been reported to bind with the Na-K-2Cl cotransporter 1 (NKCC1) in human T84 cells. Silencing IRBIT in this model decreased the cAMP-stimulated $\mathrm{Cl}^{-}$secretion presumably by decreasing the activity of $\mathrm{NKCC} 1 .^{16}$

\section{IRBIT a synergistic mediator of the CAMP and $\mathrm{Ca} 2+$ signaling pathway}

In secretory epithelia, $\mathrm{Ca}^{2+}$ and cAMP signaling pathways control secretion. Both pathways can have an additive or synergistic action. ${ }^{17-19}$ For a more detailed discussion on how intracellular $\mathrm{Ca}^{2+}$ potentiates the CAMP pathway and vice versa and synergistic effect of $\mathrm{Ca}^{2+}$ and cAMP we refer the reader to the review by Ahuja et al. ${ }^{19}$ To date, the mechanistic details behind the synergistic action of $\mathrm{Ca}^{2+}$ and cAMP remain elusive, but work in the pancreatic duct and the salivary glands has shown that IRBIT can mediate the synergistic activation of the CFTR and SLC26a6 by cAMP and $\mathrm{Ca}^{2+} .{ }^{15}$ Further work is now needed to test whether IRBIT mediates the synergistic effect of cAMP and $\mathrm{Ca}^{2+}$ in other tissues and whether additional proteins participate in the synergistic mechanism.

\section{Other functions of IRBIT}

Because of the numerous downstream targets of $\mathrm{Ca}^{2+}$ it is not 
surprising that IRBIT has additional roles other than the ones discussed above. For instance, IRBIT interacts with the cleavage and polyadenylation specificity factor, which plays a role in mRNA processing. This study suggests that IRBIT could regulate gene expression. ${ }^{20}$ IRBIT also binds to the phosphatidyl inositol phosphate kinase members, who are potent regulators of ion transporters and would provide another level of regulation for electrolyte and solute transport in cells. ${ }^{21}$ IRBIT has been reported to inhibit the calcium calmodulin-dependent kinase II alpha in the brain and thus, would contribute to the regulation of the amount of catecholamine in the brain. ${ }^{22}$ IRBIT null mice show abnormal social behavior and hyperactivity that can be attributed to the level of catecholamine. ${ }^{22}$ Most recently IRBIT has been demonstrated to be involved with cell death by blocking the Bcl2110 protein and facilitating large movements of $\mathrm{Ca}^{2+}$ to the mitochondria and thus promoting apoptosis. ${ }^{23}$

\section{Conclusion}

Although some of IRBIT's cellular functions have started to be uncovered, many unknowns about IRBIT still exist. For instance, there are two isoforms of IRBIT a short and long N-terminus IRBIT. ${ }^{24}$ Most of the studies have focused on the short $\mathrm{N}$-terminus, but the long N-terminus is also capable of binding to NBCe1-B and decreases the $\mathrm{Mg}^{2+}$-sensitivity of NBCe1-B inhibition during low $\mathrm{HCO}_{3}^{-}{ }^{25}$ The expression and distribution of the two isoforms within tissues is not known. It remains to be determined whether the long and short IRBIT share common target proteins, and if so what is the impact of each isoform on the function of the target protein. Experiments have shown that a phosphorylation state of IRBIT is critical for carrying out its functional role; however, beside this rapid regulation we know very little about the rapid regulation of IRBIT by other proteins (e.g. kinases) or IRBIT gene expression. One study shows that in avian's oviduct, estrogen agonist induced IRBIT expression in luminal and glandular epithelial cells of the oviduct. ${ }^{26}$ Because of IRBIT involvement in $\mathrm{Na}^{+}$and $\mathrm{HCO}_{3}^{-}$transport we may expect that acid-base status (e.g. metabolic acidosis, and alkalosis), blood pressure or hormones involved in $\mathrm{Na}^{+}$homeostasis (e.g. aldosterone, angiotensin II)influence IRBIT expression. Because of its role as a third messenger released from the IP ${ }_{3} \mathrm{R}$ it is expected that IRBIT will play essential roles in health and diseases.

\section{Acknowledgements}

The authors would like to thank Lynn Wellsand for her administrative assistance. PBG is supported by the Start up funds from Valparaiso University Art \& Science College and the Wheat Ridge Ministries O.P. Kretzmann Grant for Research in the Healing Arts and Sciences.

\section{Conflict of interest}

The author declares no conflict of interest.

\section{References}

1. Roman LA. Signal transduction. In: Medical Physiology A cellular and molecular approach. In: Boron WF, Boulpaep EL, editors. 2003. p. 87114.

2. Rizzuto R, Pinton P, Brini M, et al. Mitochondria as biosensors of calcium micro domains. Cell Calcium. 1999;26(5):193-199.

3. Mikoshiba K. IP 3 receptor/ $\mathrm{Ca}^{2+}$ channel: from discovery to new signaling concepts. J Neurochem. 2007;102(5):1426-1446.
4. Mikoshiba K. Role of $\mathrm{IP}_{3}$ receptor signaling in cell functions and diseases. Adv Biol Regul. 2015;57:217-227.

5. Ando H, Mizutani A, Matsu-ura T, et al. IRBIT, a novel inositol 1,4,5-trisphosphate $\left(\mathrm{IP}_{3}\right)$ receptor-binding protein, is released from the $\mathrm{IP}_{3}$ receptor upon $\mathrm{IP}_{3}$ binding to the receptor. $J$ Biol Chem. 2003;278(12):10602-10612.

6. Ando $\mathrm{H}$, Mizutani A, Kiefer $\mathrm{H}$, et al. IRBIT suppresses $\mathrm{IP}_{3}$ receptor activity by competing with $\mathrm{IP}_{3}$ for the common binding site on the IP receptor. Mol Cell. 2006;22(6):795-806.

7. Devogelaere B, Beullens M, Sammels E, et al. Protein phosphatase-1 is a novel regulator of the interaction between IRBIT and the inositol 1,4,5trisphosphate receptor. Biochem J. 2007;407(2):303-311.

8. Devogelaere B, Nadif Kasri N, Derua R, et al. Binding of IRBIT to the $\mathrm{IP}_{3}$ receptor: determinants and functional effects. Biochem Biophys Res Commun. 2006;343(1):49-56.

9. Shirakabe K, Priori G, Yamada H, et al. IRBIT, an inositol 1,4,5trisphosphate receptor-binding protein, specifically binds to and activates pancreas-type $\mathrm{Na}^{+} / \mathrm{HCO} 3$ - cotransporter 1 (pNBC1). Proc Natl Acad Sci U S A. 2006;103(25):9542-9547.

10. Lee SK, Boron WF, Parker MD. Relief of auto inhibition of the electrogenic $\mathrm{Na}-\mathrm{HCO}_{3}$ cotransporter NBCe1-B: role of IRBIT vs. amino-terminal truncation. Am J Physiol Cell Physiol. 2012;302(3):C518-C526.

11. Houillier P, Chambrey R, Achard JM, et al. Signaling pathways in the biphasic effect of angiotensin II on apical $\mathrm{Na} / \mathrm{H}$ antiport activity in proximal tubule. Kidney Int. 1996;50(5):1496-1505.

12. He $\mathrm{P}$, Zhang $\mathrm{H}$, Yun CC. IRBIT, inositol 1,4,5-triphosphate $\left(\mathrm{IP}_{3}\right)$ receptor-binding protein released with $\mathrm{IP}_{3}$, binds $\mathrm{Na}^{+} / \mathrm{H}^{+}$exchanger NHE3 and activates NHE3 activity in response to calcium. $J$ Biol Chem. 2008;283(48):33544-33553.

13. He P, Klein J, Yun CC. Activation of $\mathrm{Na}^{+} / \mathrm{H}^{+}$exchanger NHE3 by angiotensin II is mediated by IRBIT, IP 3 receptor binding protein released with $\mathrm{IP}_{3}$, and CaMKII. J Biol Chem. 2010;285(36):27869-27878.

14. Yang D, Shcheynikov N, Zeng W, et al. IRBIT coordinates epithelial fluid and $\mathrm{HCO}_{3}$-secretion by stimulating the transporters pNBC1 and CFTR in the murine pancreatic duct. J Clin Invest. 2008;119(1):193-202.

15. Park S, Shcheynikov N, Hong JH, et al. IRBIT mediates synergy between $\mathrm{Ca}^{2+}$ and cAMP signaling pathways during epithelial transport in mice. Gastroenterology. 2013;145(1):232-241.

16. Tang X, Tang J, Mykoniatis A, et al. W1779 Regulation of chloride secretion in the colonic crypt cell line T84 by Inositol 1, 4, 5trisphosphate $\left(\mathrm{IP}_{3}\right)$ Receptor-Binding protein released with $\mathrm{IP}_{3}$ regulates (IRBIT). Gastroenterology. 2010;138(5 Suppl 1):738.

17. Cartwright CA, McRoberts JA, Mandel KG, et al. Synergistic action of cyclic adenosine monophosphate- and calcium-mediated chloride secretion in a colonic epithelial cell line. J Clin Invest. 1985;76(5):18371842 .

18. Vajanaphanich M, Schultz C, Tsien RY, et al. Cross-talk between calcium and cAMP-dependent intracellular signaling pathways. Implications for synergistic secretion in T84 colonic epithelial cells and rat pancreatic acinar cells. J Clin Invest. 1995;96(1):386-393.

19. Ahuja M, Jha A, Maléth J, et al. cAMP and $\mathrm{Ca}^{2+}$ signaling in secretory epithelia: crosstalk and synergism. Cell Calcium. 2014;55(6):385-393.

20. Kiefer H, Mizutani A, Iemura $\mathrm{S}$, et al. Inositol 1,4,5-triphosphate receptor-binding protein released with inositol 1,4,5-triphosphate (IRBIT) associates with components of the mRNA 3' processing machinery in a phosphorylation-dependent manner and inhibits polyadenylation. J Biol Chem. 2009;284(16):10694-10705. 
21. Ando H, Hirose M, Gainche L, et al. IRBIT Interacts with the Catalytic Core of Phosphatidyl inositol Phosphate Kinase Type Ialpha and IIalpha through Conserved Catalytic Aspartate Residues. PLoS One. 2015;10(10):e0141569.

22. Kawaai K, Mizutani A, Shoji H, et al. IRBIT regulates CaMKII alpha activity and contributes to catecholamine homeostasis through tyrosine hydroxylase phosphorylation. Proc Natl Acad Sci U S A. 2015;112(17):5515-5520.

23. Bonneau B, Ando H, Kawaai K, et al. IRBIT controls apoptosis by interacting with the $\mathrm{Bcl}-2$ homolog, $\mathrm{Bc1} 2110$, and by promoting ERmitochondria contact. Elife. 2016:5.
24. Devogelaere B, Sammels E, De Smedt H. The IRBIT domain adds new functions to the AHCY family. Bioessays. 2008;30(7):642-652.

25. Yamaguchi S, Ishikawa T. AHCYL2 (long-IRBIT) as a potential regulator of the electrogenic $\mathrm{Na}^{+}-\mathrm{HCO} 3-$ cotransporter NBCe1-B. FEBS Lett. 2014;588(5):672-677.

26. Jeong W, Kim J, Ahn SE, et al. AHCYL1 is mediated by estrogeninduced ERK1/2 MAPK cell signaling and microRNA regulation to effect functional aspects of the avian oviduct. PLoS One. 2012;7(11):e49204. 